GERARD RAULET

\title{
Posmodernidad y democracia
}

$\mathbf{E}$ n noviembre de 1984 durante una conferencia en las Cortes; Jürgen Habermas declaró: "pienso que la tesis de inicio de la era posmoderna no tiene fundamento". Si se intenta escribir la historia de conceptos como "moderno", "modernidad", "modernismo", es verdad que la "modernidad" sólo existe como un momento de crisis en el proceso de la modernización económica, social, política y cultural, como toma de consciencia de ser "moderno" que caracteriza a las épocas de redefinición radical de las normas y los procedimientos, y así la "posmodernidad" no es más que una nueva modernidad. Sin embargo, podemos convencernos de la realidad de la posmodernidad considerando la evolución de los peligros a los que se enfrenta la democracia.

\section{Racionalismo y politeísmo de valores}

Desde el punto de vista de los efectos de la modernización, la historia de la modernidad revela una dialéctica coextensiva de la "dialéctica de la razón", cuya lógica fue descrita por Horkheimer y Adorno a mitad de los 40. Esta dialéctica desemboca en una atomización generalizada del cuerpo social y de las normas que aseguran su cohesión y constituye según la reconstrucción idealtípica desarrollada por Weber, el efecto mismo de la racionalización, inseparable del desarrollo del capitalismo. La racionalización creciente de las esferas antaño reguladas por la tradición, descompone el orden simbólico incuestionable que organizaba la vida de las sociedades tradicionales. La necesidad de movilizar la fuerza del trabajo contradecía el simbolismo del hábitat rural y del arraigo de los hombres. El "Anti-Edipo" de Deleuze y Guattari descubre en esta "desterritorialización" el proceso de la historia universal, y en el capitalismo que se afirma al término de esta evolución, la "verdad universal de esa misma historia". Desterritorialización de los productores, Vogelfreie Aroeiter arrancados de sus huertos y de sus tierras patrias,-ése es, 
según el mismo Marx, el origen del capitalismo- constituyendo fortunas comerciales o financieras y no agrarias, equivalencia general y forma mercancías, deslocalizando las necesidades en función de los deseos y, finalmente también, deslocalización sociológica aboliendo en el seno del propio capitalismo la polarización de las clases: así se puede esquematizar el proceso que Weber personalmente aprehende como modernizacion y racionalización. En su célebre Zwischenbetrachtung esta historia del "racionalismo occidental" se condensa en la fórmula según la cual la racionalización engendra el politeísmo de valores. Una deslegitimación generalizada corta en su propio desarrollo la legitimidad racional. El desencanto que hizo desaparecer el sentido, (que se supone Dios dio al mundo al crearlo) desemboca en una Sinnlosigkeit (ausencia de sentido) fundamental que deja campo libre a múltiples visiones del mundo, de Weltanschauungen. Al término de un proceso de desmitologización desarrollado persistentemente durante siglos por la cultura occidental, la lucha de dioses de distintos órdenes y de valores diferentes se mantiene sólo cambiando de forma. Estos antagonismos son insuperables; Weber rechaza la dialéctica que construye, en Hegel, su reconciliación. Solamente pueden dar lugar a compromisos provisionales y frágiles pues son objetos de evaluaciones incesantes: ése es el politeísmo de valores. La sociedad está amenazada de anomia.

Estas páginas adquieren pleno sentido hoy. Para Lyotard, en la evolución de las interacciones sociales el contrato temporal sustituye de hecho la institución permanente en las materias profesionales, afectivas, sexuales, culturales, familiares, internacionales, como en los asuntos políticos: Pero donde Weber inserta su sociología comprensiva, la "posmodernidad" se contenta aceptando y "dejando jugar" la multiplicidad de las Weltanschauungen, la división hacia el infinito de la sociedad que el Hyperion de Hölderlin describía como la maldición de la modernidad, en la que Marx veía la característica de las sociedades "realmente modernas", y que para Daniel Bell se radicaliza en la era "postindustrial" multiplicando los riesgos de enfrentamiento.

¿Es esta situación de anomia, una situación de crisis que amenaza la supervivencia y la reproducción de las sociedades regidas por esta racionalidad? En Legitimationsprobleme im Spätkapitalismus, Habermas se esforzó en adaptar la teoría de la crisis a la realidad nueva del "capitalismo avanzado". Piensa que una crisis sólo es evitable cuando los miembros de una sociedad consideran las' transformaciones estructurales críticas para la 
existencia misma del sistema y sienten que su identidad social está amenazada, es decir cuando el consenso, base de las estructuras normativas, está mermado hasta tal punto que la sociedad se vuelve anómica. El consenso funciona como un verdadero "transformador" de la crisis. En efecto, los intercambios entre sistemas sociales y su entorno se efectúan en dos órdenes epistemológicamente irreductibles: mientras la apropiación de la naturaleza externa (el trabajo) depende de datos susceptibles de verdades y una racionalidad instrumental, la socialización (apropiación de la naturaleza interna) depende de estructuras normativas y se realiza gracias a normas que necesitan una justificación.

Esta actualización nos parece que no acertó en su captación de la realidad del funcionamiento de nuestras sociedades democráticamente desarrolladas. La anomia no conduce necesariamente al estallido de una crisis, sino que sólo constituye una situación de crisis endémica y larvada cuya economía debe ser estudiada independientemente de una filosớfia de la historia según la cual las situaciones de crisis inducen "giros históricos". La crisis endémica y larvada representa actualmente de forma más clara un modo de funcionamiento de las sociedades democráticas occidentales cuya normalidad reside en la anomalía, por la simple razón de que: "el politeísmo de valores" ofrece a la expresión democrática un espacio de libertad insospechado.

La cuestión es, ciertamente, saber si esta expresión democrática, tomando la forma de expresividad, no es al mismo tiempo el peor enemigo de la democracia. El paso hacia una era antidemocrática, totalitaria o terrorista, podría hacerse muy bien sin conmociones violentas, sin revolución ni golpe de Estado, solamente en virtud de una autodestrucción de la democracia, al expandirse la expresión individual acompañada de un desinterés creciente hacia alternativas políticas. La democracia moriría entonces de hipertrofia, de su "obesidad", como diría Baudrillard.

Este peligro en su principio es bien conocido: lo difuso de la voluntad general que, por excesiva voluntad de transparencia, es una de las tareas ciegas del Contrat Social de Rousseau, que motivara la distinción fundamental de Kant entre republicanismo y democracia.

¿Es aún posible una "voluntad general"? ¿Qué sentido tiene hoy la "voluntad de todos"? 


\section{Dialéctica de la publicidad}

El problema se encuentra en la transición de la "voluntad de todos" a la voluntad general. Incluye tambiénda pregunta: ¿El sistema de representación política establecido (mediante luchas que no habrá que olvidar) permite aún esta mediación, o está colocado ya fuera de juego por el politeísmo de valores que afecta a la voluntad de todos? Para contestar a esta doble pregunta hay que recordar brevemente el destino de las instancias mediadoras, de los "transformadores", un destino que obedece a una dialéctica de la publicidad, parelela a la dialéctica de la racionalización.

En el siglo XVIII, el discurso universalista de la Razón se afirma por una parte, en Kant, como una idea moral universlamente válida, fundada a priori en la razón pura práctica pero, por otra parte, se identifica también el consenso empírico reinante en el público culto sobre un fondo de ideas que constituye, en realidad, "el bien común de la razón burguesa" (Thomasius). La tercera crítica de Kant tenderá, entre otros fines, a establecer un acuerdo entre la Razón y el sentido común (Gemeinsinn), también llamado "sentido comunitario" (gemeinschaftlicher Sinn). En los escritos de filosofía práctica la categoría de publicidad asegura una mediación dinámica, haciendo pasar las máximas de la Razón (publicidad de máximas) hacia el público de lectores. Lo mismo pasa con el diálogo en los Diálogos masónicos de Lessing. Además de la intervención de un momento capital para toda reflexión sobre el funcionamiento de la democracia, Lessing revaloriza ( $y$ con ello da fundamentos a la francmasonería) la función del secreto, mientras que para Kant el republicanismo sustituye, con una representación mediata, a la transparencia inmediata.

La francmasonería ideal de Lessing simboliza el acuerdo entre hombres preclaros o ilustrados; lejos de estar encerrada en sí misma, está abierta a todos, es universal y todos los que usan la Razón son miembros de derecho. Representa en el seno de la sociedad existente el germen aún secreto de la sociedad perfecta. Pero precisamente porque esta sociedad perfecta no es un concepto (no corresponde a una realidad empírica) sino una Idea, los francmasones están investidos para una misión pedagógica basada doblemente en el secreto y en la publicidad: tienen que ayudar con el diálogo (publicidad) a cada individuo dotado de razón a descubrirse "Francmaçon", ciudadano de la sociedad ideal, sin jamás afirmar dogmáticamente su verdad, pues este secreto que es el suyo no puede revelarse como concepto, como conocimiento empírico. Este secreto no es más que la práctica, 
que empieza con el diálogo. Esta reivindicación de la historia por un público ilustrado que afirma su vocación universal sugiere dos conclusiones: primero, la hegemonía de la Ilustración mediante la formación de la opinión pública, después y sobre todo, el temor de un abuso de la Ilustración, que se traduce en Lessing por la dialéctica secreto-publicidad y en Kant por la distinción entre el hombre público (el erudito, sujeto pensante, dirigiéndose a otros sujetos pensantes) y el hombre privado (el sujeto empírico realizando su Beruff). Es este temor el que conduce a Lessing a justificar la práctica del secreto y de la mentira pedagógica, preconizando que las verdades y actos ad extra están siempre adecuados al consenso existente en cada momento en el cuerpo social. Entre el ideal y la ideología, el secreto aparece como un transformador tan importante como la publicidad, precisamente para evitar la transparencia total que reduciría el consenso a su estado empirico.

En la evolución de la publicidad burguesa el Estado ha tenido que jugar este papel de regulador. La "dialéctica de la publicidad" puede esquematizarse de este modo: la noción de publicidad hace valer contra el derecho establecido la dinámica de una opción pública, de un consenso, en ósmosis con la moral. Este consenso afirma así su derecho a fundar la nueva legalidad; además, así se impuso la forma constitucional del Estado moderno. Pero también así este Estado fue investido de la función de regulación y heredó la función mediadora del secreto reanudando su tradición maquiavélica -o más bien asumiéndola de hecho sin ruptura en un contexto nuevo- puesta al servicio del buen hacer de la Ilustración: El Estado se convierte en gerente del consenso, de la mediación entre ideal e ideología. Con este concepto institucionaliza y neutraliza la ambigüedad subyacente a la publicidad de la Ilustración entre la Razón y las pretensiones universalistas de una clase, el Hombre y el burgués. Los derechoš fundamentales garantizarán a la vez el uso público de la Razón (libertad de opinión, de palabra, de prensa, de asociación y de reunión; derecho al voto, de petición, y, en cierta medida, a ser elegido), el libre estatuto del individuo (libertad de la persona) y los intercambios entre propietarios (igualdad ante la ley, protección de la propiedad privada). Entre estos tres aspectos no hay discontinuidad, por lo menos durante la fase ascendente del capitalismo, que vio en la libre competencia e intercambio el libre acceso a la esfera pública - la cultura y la propiedad-. Era perfectamente creíble que la esfera pública fuera expresión del interés general, que el burgués propietario defendiera al Hom- 
bre y a la Razón. Ahora bien, la contradicción real de los intereses de los propietarios y de los no propietarios, disimulada por el universalismo de la opinión pública burguesa encubre un potencial de conflictos, que solamente la ficción de un Estado situado por encima de los partidos y de los intereses de clases puede contener. Para superar el conflicto disimulado detrás de la publicidad burguesa, Hegel introduce una figura del Estado que anticipa con lucidez, aunque al precio de una regresión en cuanto a formas políticas propuestas, la evolución real del Estado constitucional burgués. Pues la publicidad burguesa acaba, de hecho, engendrando su contrario: el Estado burocrático (lo que ya es verdad para el pacto entre la burguesía alemana y el Estado prusiano), el Estado que Marx y Engels verán realizado con el Segundo Imperio y, finalmente, el Estado social del capitalismo avanzado que trata de reducir todos los problemas de legitimidad a problemas técnicos.

Sólo esta autodestrucción dialéctica de la publicidad de la Ilustración permite de momento explicar que en la evolución del capitalismo el régimen parlamentario no se haya convertido en enterrador del dominio burgués. Por las reformas sucesivas del derecho de voto, la masa de la opinión pública plebeya ya tendría que haber hecho irrupción en la publicidad política.

Este Estado transformador, que interviene incluso cuando debe actuar en contra de los intereses dominantes con el fin de salvaguardar el equilibrio del sistema, no cesó sin embargo de extender sus poderes y de consolidar sus cimientos, desconectando cada vez más los problemas de racionalidad de los problemas de legitimidad, es decir, sustituyendo al consenso del cual es gestor, la racionalidad misma de esta gestión, el conjunto ciencia-técnicaadministración.

Mientras que en el siglo XVIII, la publicidad expresaba un consenso social que pretendía institucionalizar una voluntad colectiva de transformación, hoy ésta ya no constituye la legitimidad del poder político ni inspira su racionalidad. Según Habermas, la mediación toma la doble forma de "refeudalización" y de "vasallajización", de una invasión de la sociedad civil por intervenciones del Estado y de una privatización de la esfera pública por la lucha que le oponen los lobbies de intereses privados; si la opinión pública sobrevive aún, es "avasallada" sobre todo por los mass-media.

Ese diagnóstico es válido si se ponen bien los acentos. Lo esencial es, en efecto, la reprivatización del dominio público, no el espectro del Estado. A primera vista la supremacía de la racionalidad instrumental se impone como extensión del poder para 
disponer técnicamente de las cosas (technische Verfügungsgewalt) en la gestión de la integración social. Desde este punto de vista, decisiones y normas tienden cada vez más a justificar la legitimidad de su eficacia (Luhmann, Legitimation durch Verfahren, 1969). Pero paralelamente, desvinculando las elecciones de la justificación por valores establecidos o universalizables gracias a una publicidad racional, esta extensión de racionalidad técnica multiplica las alternativas individuales y deja libre curso al individualismo de intereses. La alternativa "más Estado o menos Estado" no tiene nignún sentido ante la dialéctica de la racionalización y de la publicidad. Más radicalmente aún, esta evolución "cortocircuita" a los transformadores, no sólo la formación de una nueva voluntad colectiva sino al Estado mismo.

\section{Mediatización y mass-media; desaparición de transformadores}

¿Qué aspecto tiene hoy la esfera pública? Se considerará lo que sigue como una reflexión sobre potencialidades o tendencias inscritas en nuevas formas de comunicación social. El desarrollo de nuevas tecnologías de comunicación tiene efectos, en todo caso, que ponen fuera de juego las instancias mediadoras y promocionan la llegada de una nueva transparencia democrática ante la que deberíamos preguntarnos si no remata, bajo la apariencia de permitir una democracia increíble, la autodestrucción de la publicidad.

Excrecencia de la información desembocando en la inercia, obesidad de los sistemas de memorias, de almacenamientos de información que ya, hoy, no son procesables, la tendencia existe evidentemente. Sin embargo, nos parece menos decisiva que el crecimiento de capacidad de contenidos, es decir, de capacidades de almacenamientos, de redes y de comunicabilidad. El desarrollo del Minitel (micro ordenador conectado a redes telefónicas) en Francia obedeció a una lógica exclusivamente industrial y comercial; la naturaleza de mass-media del producto interviene en segundo plano. De modo que junto al problema de la "conexión" a lo social -asociaciones, grupos de afinidades, hobbies... - existe el de las "prótesis", como dicen los especialistas. Porque, dado que la herramienta precedió a sus necesidades y contenidos, aún se están buscando nuevas utilizaciones. Actualmente somos capaces de hacer circular datos aún más de prisa, pero ¿qué datos y para qué? Claro que se puede pensar que son los usuarios, los sujetos sociales quienes tienen que "elegir" el contenido. La cuestión entonces es saber qué hará con los sujetos el desarrollo de estas 
nuevas tecnologías; la dominación y resocialización de éstas dependen de una multiplicidad de alternativas posibles, de las cuales habría que legitimar los criterios.

Los grupos podrian reconstruir las normas, pero, potencialmente, la reconstrucción de tal base normativa y la formación en sí de grupos está minada por la naturaleza de rizomas de las redes. Remplazando a los grupos como foco de una comunidad normativa, unos lobbies podrían confiscar los canales con fines estratégicos. Además existe la propensión de las nuevas tecnologías a desarrollar y sustituir mercados ya constituidos y a reforzar redes establecidas. Teniendo en cuenta la ausencia de contenidos sociales y la crisis de criterios, las hipótesis más plausibles son las del mantenimiento de las estructuras sociales, comerciales o de información establecidas, incluso su fortalecimiento y el riesgo de formación de lobbies. Pero la gravedad de la crisis de criterios no es sólo la de dejar en suspenso las esperanzas sociales frente a los mass-media recientes, sino que crece al democratizarse su uso. Con la mayor democratización de su uso, aumenta la arbitrariedad de la expresividad individual frente a toda normativa.

En cuanto al espectro de la intervención del Estado, no solamente cae en la trampa del adagio weberiano según el cual no hay producción de sentido administrativo, sino que además esa diseminación "democrática" lo reduce a la impotencia.

Esos efectos de las nuevas tecnologías se inscriben en la evolución más general que sustituye a los "Grandes Relatos" por muchos pequeños relatos expresivos que son en sí mismos su propia norma.

La socialización ya no se realiza mediante normas que deban justificarse o sea la publicidad, ni siquiera por la instancia en que ésta tradicionalmente había delegado: el Estado gerente del consenso. En el intercambio social pre-moderno o moderno (regulado por la tradición o por normas válidas universalmente) la subjetividad nunca intervenía directamente sino mediatizada simbólicamente por las reglas colectivas. "Un tercio simbolizante" cuyo papel era mantener la referencia a una esfera ante o meta-comunicacional o bien totalmente implícita, como en el caso de la convivencia en las sociedades tradicionales o sus supervivencias (en particular rurales) o bien tematizada por la moral racional, pero situándose sin embargo a otro nivel que el de intercambio empírico. El Estado republicano, como expresión de la voluntad general, era también heredero de esta mediación. Con la desaparición del "tercio simbolizante" normativo la "comunicación" se desvía hacia otros juegos de lenguaje: Una expresividad indivual literal- 
mente sin reglas, que progresa hacia lo cognitivo y lo performativo.

\section{Transparecia y obscenidad}

Los pequeños relatos individuales expresivos, de lo que vi, de lo que sentí, de lo que viví, sin ningún maquillaje, sin ninguna falsificación ni puesta en escena de mi experiencia, señalan la llegada de una comunicación-revelación situada bajo las exigencias de expresividad personal, del destape mutuo de los individuos (opciones y sentimientos). El estudio sociológico y psicológico de las redes "Minitel" es particularmente instructivo en este sentido. Aquí la transparencia democrática se vuelve obscena llevando al límite la confusión entre la voluntad general y la voluntad de todos, transformando incluso la voluntad de todos en la afirmación de voluntades individuales.

Según Richard Sennett (The Fall of Public Man, Nueva York, 1974) la interacción social se asienta sobre una escenificación: el hombre público, en oposición al hombre privado, sacrifica su subjetividad, sentimientos y deseos, por respeto a una convención. La subjetividad nunca se revela de inmediato, sino siempre en función de reglas colectivas que introducen una opacidad necesaria en la transparencia de la comunicación (cfr. supra Lessing). Es esa opacidad la que distingue a la comunicación de la simple información, lo normativo de lo cognitivo. El consenso no es una ecuación, sino un acuerdo obtenido por argumentación. Ésta no borra los conflictos pero pone en marcha la referencia a una instancia en la cual los protagonistas llegan a un acuerdo. Esta instancia en el siglo XVIII no era del orden del entendimiento, sino del de la universalidad de la Razón; el consenso extraía su legitimidad y su eficacia práctica del interés general, que no se identificaba con el interés de todos. "La transparencia y la obscenidad del espacio en la promiscuidad de las redes" (Braudrillard).

La desaparición de la "escenificación" desemboca en esta "obscenidad blanca", que Braudrillard describe así:

Todos somos actores, todos espectadores, ya no hay teatro, el teatro está por todas partes, ya no hay reglas, cada uno representa su propio drama, improvisa sobre sus propios fantasmas... Esta obscenidad blanca, esta escalada de la transparencia, alcanza su cumbre con el hundimiento del escenario político. A partir del siglo XVIII, éste se moraliza y se vuelve serio. Es un lugar con un significado fundamental: el pueblo, 
la voluntad del pueblo, las contradicciones sociales, etc. Ha de corresponder al ideal de una buena représentación. Mientras que la vida política anterior, como la Corte, actuaba de un modo teatral, a base de juego y maquinaciones, desde este momento existe un espacio público y un sistema de representación (la ruptura se instala simultáneamente en el teatro con la separación del escenario y de la sala). Es el fin de una estética y el principio de una ética de lo político... Lo obsceno nace fuera del escenario, en las tramoyas del sistema de representación. Primero es, pues, oscuro: es lo que derrota la transparencia del escenario como lo inconsciente y lo inhibido derrotan la transparencia de la conciencia. (...) Tal es la obscenidad tradicional, la del inhibido sexual o social, de lo que no es representado ni representable. Para nosotros no es lo mismo: Hoy al contrario la obscenidad es la de la sobrerrepresentación. (...) Al principio había el secreto, después hubo lo inhibido y luego hubo que jugar a la profundidad. Al fin hubo lo obsceno y fue la regla de juego de un universo sin apariencias ni profundidad -de un universo de la transparencia. Obscenidad blanca.

Pero por ser blanca, es decir moralmente neutral, no es menos peligrosa, sino más peligrosa aún para la democracia. Porque si el secreto de los príncipes o el de los lobbies es realmente su enemigo, la utopía de la transparencia es tan nefasta para la representación democrática como la desaparición del ceremonial para la representación feudal.

En efecto, la voluntad de todos toma la forma de un parcelamiento generalizado que no sólo es incapaz de crear un verdadero consenso, sino que también libera una expresividad estratégica, incluso terrorista, una omnipotencia de género performativo cuyo estallido es inseparable. Aquí también los usos "interactivos $^{\text {n }}$ de nuevas tecnologías de comunicación pueden hacer entender esta evolución. La propia cxpresividad que los invistió es fundamentalmente estratégca, sin distinguirse apenas de los video-juegos basados en la agonística y la estrategia, en la invención de golpes. Una encuesta de Eddie Cherky sobre la red "Minitel" de Estrasburgo ("Gretel") muestra que el diálogo por "Minitel" da lugar no solamente a la invención de relatos individuales que son (frecuentemente, si no por principio) identidades ficticias -con lo que la anomia deviene regla- sino que también da lugar a un juego estratégico que consiste en esconderse o en descubrir ("destapar"). Más aún, la "piratería", es 
decir la invención deliberada de falsas identidades, consiste en no cortarse, en no dejarse descubrir, pero también en cambiar de identidad (y, notémoslo, de sexo).

Si la performatividad y la expresividad -en realidad estratégica- remplazan cada vez más a la argumentación enfocada a un acuerdo sobre normas, la única alternativa verdadera es la del totalitarismo ("performativo") y del terrorismo expresivo, cuya subjetividad confisca y pervierte la subjetividad de la moral. Al fin de La condición posmoderna, Lyotard sugiere esta alternativa:

La informatización de las sociedades puede convertirse en la herramienta "soñada" para el control y regulación del sistema de mercado, extendido hasta el saber mismo, y exclusivamente dirigido por el principio de "performatividad". Y así comporta de forma inevitable el terror. Puede servir también a los grupos de discusión sobre los metaprescriptivos dándoles la información que necesitan a menudo para decidir con conocimiento de causa.

Sin embargo, Lyotard no consigue "desintrincar" el totalitarismo del terrorismo. Se niega a ver que el peligro del terrorismo democrático, resultado del exceso de transparencia, es más urgente ahora, si cabe, que el peligro de totalitarismo y llama a la isomorfia "terror" cuando es, de hecho, totalitarismo. Por cierto, es la supremacía de la virtud moral la que engendró el terror jacobino, pero precisamente porque la Virtud se separó del cuŕso del Mundo (Hegel) y permaneció como discurso subjetivo. El totalitarismo empieza donde lo subjetivo y lo objetivo pretenden no distinguirse el uno del otro, (y no importa que recurra al Espíritu o a la vida), donde toda clase de discurso se legitima con un mismo fundamento que lo justifica todo, incluso el Mal en la Historia.

\section{5. ¿Cómo salvar la democracia?}

Haciendo abstracción del rearme moral, ¿cómo reconstruir el "tercio simbolizante" que, asumiendo realmente su función de transformador, frenaría el territorismo y el totalitarismo?

A su manera, la reflexión de la arquitectura posmodena abri 6 algunas perspectivas. La noción de codificaciones múltiples propuesta por Charles Jencks debe permitir a la arquitectura dirigirse a todos, a las masas como a la élite. Se apoya, primero, en la yuxtaposición de dos códigos, el de la lectura común y el de 
la lectura de lo expertos, pero también en un eclecticismo y un aluralismo estilístico que, por sus recursos historicistas a los eslos del pasado, asegura al nivel formal la legitimidad de una radición que niega invocar como tal, pero que, unido a la pluralidad de lecturas posibles, parece poder constituir el más amplio consenso posible, apoyando en un público de extrema diversidad. Esta nostalgia del consenso, lejos de constituir el metadiscurso normativo que cimienta el lazo social, confirma sin embargo su descomposición y se contenta con reflejarla: la codificiación múltiple es, en realidad, lo que Deleuze y Guattari llaman "la decodificación", la destrucción de los códigos, la desterritorialización.

Todos los movimientos arquitectónicos posmodernos testifican una misma ambivalencia. Cuando no promueven un pluralismo sacado de un neo-liberalismo, sus intenciones democráticas resbalan hacia el "anti-modernismo".

Dignas de interés son las tentativas dirigidas a la promoción de una arquitectura comunal (municipal) que no sólo se contenta de asociar los intereses a la planificación al nivel de grandes discursos, sino que también elabora planos de barrios dialogando con los clientes. Si, en el ámbito del urbanismo, los mecanismos de management del mercado y de las administraciones funcionan de manera que comportan a los interesados disfunciones -e invalidan así el "funcionalismo", en el sentido en que se entendía clásicamente-, es lógico entonces hacer concurrir junto al dinero y el poder, la comunicación, a través de la cual los intereses configuran una voluntad colectiva. Pero, la nostalgia de formas de vida uniformizadas, retrocediendo hasta el límite de toda diferenciación, da muchas veces a esas tendencias un lado antimodernista... Esa ideología de menor complejidad abdica del potencial racional y la idiosincrasia de la modernidad cultural.

Por un lado, tales tentativas rompen el discurso monológico del funcionalismo y toman el contrapié de la tendencia que remplaza la acción comunicacional por interacciones mediatizadas y sustituye a la lengua, en su función de coordinación de la acción, por mediaciones del dinero y del poder. Por otro lado, la "relocalización", la vuelta a lo local; por ejemplo al policentrismo de pequeñas ciudades (Paolo Portoghesi: small is beatiful) o aún el "regionalismo crítico" de un Kenneth Frampton, que desemboca en un "populismo estético" que podemos con- 
siderar con derecho propio como neo-conservadurismo. Deleuze y Guattari denuncian justamente esas "reterritorializaciones" como regresivas e incluso reaccionarias.

Esas ambivalencias llaman la atención sobre la ambigüedad de la descentralización que la cultura promovida por las nuevas tecnologías de comunicación debe permitir. Los intérpretes "optimistas" de esa evolución sitúan la esperanza de un "buen uso social", de una resocialización de una tecnología que tienen por simple instrumento, en la "relocalización" que favorece:

En realidad, el desarrollo de los mass-media y de las telecomunicaciones permite conferir a lo local otro tipo de función que la de mero punto terminal de recepción de un influjo venido dei centro y elaborado a su manera. La aventura de las radios libres es ya explícita: supieron volver a dar forma y expresión a la fragmentación de las tierras, a la diferenciación de públicos, a la diversidad de usos y de "dialectos". (...) También las experiencias de telemática hace ver que la mensajería y la interactividad permiten romper la inmovilidad de redes locales y entrar en relación con nuevos interlocutores para tal o tal proyecto de interés común.

Hemos visto más arriba lo que hay que pensar de todo esto. Tales esperanzas confunden descentralización y descentralización-deslocalización. Pero, es esta última la que se inscribe en el desarrollo de nuevas comunicaciones: una especialización tal que prohibe toda localización, llevando a cabo la disolución’de lazos y lugares que estructuraban simbólicamente las sociedades tradicionales. La deslocalización toma la forma de una circulación en todas direcciones que ensalza una metafórica de los flujos y la fluidez, que expresa la comunicación ideal y glorifica, como el capitalismo, "el cambio generalizado", la comunicabilidad ilimitada y la conmutación. En las redes de las nuevas comunicaciones todos los lugares son equivalentes e intercambiables, en la medida en que, en principio, todos son accesibles desde cualquiera de ellos. Como en el eclecticismo de la arquitectura posmoderna, todos los estilos se vuelven intercambiables. Precisamente esa arbitrariedad provoca la expresividad a la cual no podemos resistir más que valiéndonos de la referencia neo-conservadora de las tradiciones locales.

No obstante, estos intentos tienen el gran mérito de pecar por exceso de empirismo y de quedarse "enganchados" en la dinámica de la evolución, que les lleva al fracaso. No se puede decir lo 
mismo de la "teoría de la acción comunicativa" de Habernas, que trata de salvar el funcionamiento democrático de nuestras sociedades con una lógica de la argumentación que resucitaría la publicidad de la Ilustración. En efecto, no va hasta el límite de sus presupuestos, al cabo de la lógica que le da fundamento y al término de la cual tendría que decidirse justamente por el doble triunfo del expresionismo y de lo performativo. Si releemos con Habernas la "dialéctica de la racionalización", se ve que es esa dialéctica la que revela y construye el "contenido normativo" antaño implícito en las sociedades tradicionales; su mundo vivido se moraliza y se teoriza y lo "que considerábamos sin problema como un hecho o una norma puede ahora ser válido o no serlo". La acción comunicativa es en sí el resultado de la traducción, de la explicitación, de la tematización y de la problematización, es decir, de la racionalización del mundo vivido tradicionalmente (y de los presupuestos implícitos de toda interacción). Si esta racionalización desemboca en una expansion general, la racionalidad comunicativa debe tener un papel en esta expansión. Entonces se cuestiona su capacidad de frenarla y de reconstruir un consenso superando los contratos temporales. Pero Habernas renunció al a priori de una comunidad comunicativa trascendental, como la que sostiene Apel, y a lo "cuasi trascendental" de la historia de una clase o de la especie.

No podemos ya presuponer un momento normativo fuera de los avatares del proceso de racionalización. Es a partir de los juegos de lenguaje dominantes que debe reconstituirse un "tercio simbolizante". Querámoslo o no, la salvaguardia de la democracia pasa hoy la prueba de su mayor peligro: por abajo. En el contexto de la desterritorialización, pasa por la aptitud de las constelaciones consensuales para convertirse en verdaderos agentes sociales. Aunque es cierto que nada garantiza que esas constelaciones no sean otra cosa que "los contratos temporales" de los que habla Lyotard. Pero como él dice también (aún confundiendo totalitarismo y terror), constituyen una línea de resistencia a la isomorfia (totalitaria) y al terror de arbitrariedad expresiva que tiende a sustituir al terrorismo de la moral. Todo depende de su capacidad de construir, o por lo menos expresar, un sentido común (Gemeinsinn) o comunitario (gemeinschaftlicher Sinn), el cual no es ni cognitivo ni propiamente normativo, sino una hipótesis. Una pura constelación estética y no "momento incondicionado" derivado de una argumentacion racional que, por el contrario de lo que aún cree Habermas, simplemente ha dejado de ser posible o-para decirlo con más prudencia- lo es cada vez menos. 